\title{
PENGARUH WEB BASED LEARNING TERHADAP HASIL BELAJAR DITINJAU DARI SELF-DIRECTED LEARNING
}

\author{
Krida Puji Rahayu \\ Program Studi Manajemen, Universitas Pamulang. \\ Email: kridapujirahayu@gmail.com
}

\begin{abstract}
Abstrak
Tujuan penelitian ini adalah untuk mengetahui pengaruh dan interaksi antara pembelajaran kimia dengan model web based learning menggunakan moodle dan blog terhadap hasil belajar kognitif siswa kelas X pada materi ikatan kimia ditinjau dari kemampuan self-directed learning $(S D L)$ siswa yang berbeda. Penelitian ini menggunakan rancangan penelitian eksperimental semu yaitu posttest onlynonequivalent control group design. Pengambilan sampel menggunakan teknik cluster random sampling. Data penelitian adalah hasil belajar siswa yang dikumpulkan menggunakan instrumen berupa tes objektif yang terdiri dari 35 soal tes materi ikatan kimia dengan validitas isi sebesar 81,8\% (sangat tinggi) dan koefisien reliabilitas dihitung dengan menggunakan KR-21, sebesar 0,88 (valid dan reliabel). Uji hipotesis menggunakan statistik uji ANAVA dua jalur melalui bantuan program SPSS 16 for Windows. Hasil penelitian menunjukkan bahwa: (1) tidak ada perbedaan hasil belajar siswa yang dibelajarkan dengan model web based learning baik yang menggunakan media blog maupun moodle; (2) ada perbedaan hasil belajar kognitif siswa ditinjau dari kemampuan self-directed learning baik yang dibelajarkan dengan media blog maupun moodle; (3) terdapat interaksi antara model pembelajaran dan kemampuan self-directed learning terhadap hasil belajar kognitif siswa.
\end{abstract}

Kata Kunci : web based learning, self-directed learning

\begin{abstract}
The purpose of the research is to determine the effect of and interaction between chemistry learning with web-based learning models using moodle and blog on the cognitive learning outcomes of students class grade $X$ on chemical bond material in terms of the self-directed learning (SDL) ability of different students. This research uses a quasi-experimental research design, namely the posttest-only non equivalent control group. Sampling is conducted applying cluster random sampling technique. The research data are student's learning outcomes collected using the instrument in the form of objective test consisting of 35 questions related to chemical bond material with the content validity of $81.8 \%$ (very high). The reliability coefficient calculated using the KR-21 is 0.88 (valid and reliable). Test of the hypothesis is conducted by using two-wayANOVA in SPSS16 statistics program for Windows. The results of the research show that: (1) there is no difference in cognitive learning outcomes of students learning with web-based learning models using either blog or moodle media; (2) there is a difference in cognitive learning outcomes of students in terms of the self-directed learning ability of students learning either with a blog or moodle media; (3) there is an interaction of the learning model and self-directed learning ability with cognitive learning outcomes of students.
\end{abstract}

Key Words : web-based learning, self-directed learning

\section{PENDAHULUAN}

Ilmu kimia merupakan salah satu cabang ilmu pengetahuan alam yang mempelajari komposisi, struktur, sifat, dan reaksi pada materi [1]. Ciri khusus ilmu kimia adalah konsepnya yang bersifat abstrak, berurutan, dan berkembang dengan cepat. Ilmu kimia tidak hanya sekedar berisi pemecahan tes, akan tetapi jumlah $n$ cabangnya sangat banyak dengan karakteristik setiap topik yang berbedabeda [2]. Ikatan kimia termasuk salah satu topik dari ilmu kimia yang merupakan ilmu yang memiliki banyak konsep dan topik yang bersifat abstrak. Konsep ikatan kimia yang bersifat abstrak sangat penting karena menjadi konsep dasar untuk mempelajari konsep kimia lebih lanjut sehingga harus dipahami dengan baik dan benar. Misalnya, materi seperti laju reaksi, 
asam dan basa, elektrokimia, kesetimbangan kimia, dan kimia larutan [3]. Pemahaman konsep dasar merupakan sesuatu yang sangat penting untuk mencegah terjadinya kesalahan konsep awal bagi siswa [4].

Pemahaman konsep abstrak dalam ilmu kimia diperlukan kemampuan berpikir tingkat tinggi [3]. Siswa harus mampu menggunakan daya imajinasi dalam membayangkan gambaran untuk memahami konsep kimia secara utuh. Pemahaman utuh dapat dilakukan dengan mengenal konsep dari tingkat simbolik, makroskopik, mikroskopiknya. Ketiga level multi representasi tersebut harus terintegrasi secara proporsional dalam pembelajaran, karena mengandung konsepkonsep yang tidak dapat dipisahkan. Kemampuan representasi kimia siswa sangat dipengaruhi proses pembelajaran di kelas, praktikum di laboratorium, dan buku-buku/sumber pembelajaran yang digunakan [5]. Sehingga untuk memahami konsep ikatan kimia yang abstrak sangat dibutuhkan sebuah model pembelajaran yang mampu membantu siswa dalam memvisualisasikan konsep abstrak tersebut. Salah satu model pembelajaran yang dapat digunakan adalah menggunakan model pembelajaran yang memanfaatkan bahan ajar yang dapat menyediakan media yang memuat ketiga representasi baik makroskopik, simbolik, maupun mikroskopik secara proporsional. Model pembelajaran yang tepat yaitu model pembelajaran berbasis Web Base Learning (WBL).

Strategi pembelajaran dengan model $W B L$ merupakan model pembelajaran yang mengkombinasikan antara pertemuan tatap muka di kelas (in-class session) dengan pembelajaran secara online. Prinsip dasar penggabungan dari pengalaman belajar tatap muka dan online adalah komunikasi langsung tatap muka dan komunikasi tertulis online menggunakan sebuah media berupa jaringan internet. Pembelajaran dengan model $W B L$ dapat menggunakan open source berupa moodle dan blog. Media pembelajaran berbasis moodle dapat dilakukan secara langsung (synchronous learning) maupun tidak langsung (asynchronous learning) [6], [7].

Perbedaan di antara kedua media online antara moodle dan blog terletak pada jenis komunikasi yang disediakan oleh media tersebut. Kedua media tersebut dapat dimanfaatkan guru dan siswa dalam mengkonstruksi konsep dengan baik dan benar. Pada komunikasi asynchronous, siswa dengan leluasa dapat berinteraksi tanpa batasan waktu dan mendiskusikan masalah yang lebih kompleks sehingga saat ditanya, siswa memiliki waktu untuk berpikir dan mencari jawaban yang tepat dan tidak frustasi.

Berbeda dengan komunikasi synchronous, guru dan siswa dapat berinteraksi serta memperoleh konfirmasi, umpan balik maupun jawaban secara langsung [8]. Menurut [9] Media pembelajaran secara online baik dengan media berupa moodle dan blog dapat menciptakan lingkungan belajar yang membantu siswa menguasai suatu konsep materi. Konsep di sini yang lebih ditekankan yaitu pemahaman tentang ikatan kimia. Di mana pada konsep ini memiliki sifat konsep yang abstrak. Strategi pembelajaran dengan WBL ini diharapkan siswa dapat memvisualisasikan konsep abstrak dengan model statis seperti gambar, grafik, simbol, dan video maupun bentuk dinamis seperti animasi [10], [11].

Desain pembelajaran $W B L$ menggunakan berbagai fasilitas yang ada dapat membantu bagi guru untuk menciptakan lingkungan belajar yang aktif bagi siswa. Pembelajaran $W B L$ menuntut keterlibatan siswa untuk berpartisipasi aktif dalam belajar [9]. Hal ini dikarenakan untuk 
mendapatkan materi dan memperoleh informasi diperlukan keaktifan siswa.

Kemampuan mengakses informasi yang dilakukan siswa baik dengan media moodle maupun media blog memiliki cara berbeda. Hal tersebut dikarenakan siswa memiliki kemampuan yang berbeda untuk mengaktifkan diri mereka dalam belajar. Beberapa kemampuan yang digunakan untuk meningkatkan keaktifan siswa dalam pembelajaran dengan model $W B L$ adalah kemampuan self-directed learning, kemampuan self-directed learning dalam diri siswa dapat ditinjau dari selfmanagement, self-control, dan desire for learning. Kemampuan yang ada dalam diri siswa tersebut memungkinkan siswa memiliki regulasi dan kontrol dalam aktivitas belajar mereka sendiri. Kemampuan Self Direct Learning (SDL) merupakan kemampuan yang dibutuhkan siswa untuk dapat mengarahkan diri mereka. Ini yang merupakan komponen utama dalam mensukseskan pembelajaran WBL baik di kelas moodle maupun blog untuk memperoleh hasil belajar yang lebih baik [12].

Menurut Slavin, model pembelajaran berbasis web terdapat struktur belajar yang menuntut siswa untuk berlatih mandiri [2]. Media pembelajaran yang digunakan sudah menyediakan materi dan tugas yang memungkinkan adanya interaksi terbuka dan efektif antara guru dan siswa. Keadaan ini akan membuat siswa lebih mudah memahami konsep-konsep yang sulit sehubungan dengan masalah kompleks yang dihadapi dalam suatu pembelajaran. Hal tersebut selaras dengan penerapan model $W B L$ yang menuntut siswa untuk bisa mengontrol dan membimbing pembelajarannya secara mandiri. Penelitian dengan model Web Based Learning WBL dan kemampuan selfdirected learning terhadap hasil belajar siswa didukung dari hasil penelitian yang telah dilakukan [12], [13], [14]. Selain itu, secara lebih spesifik lagi bahwa jika model Web Based Learning dengan media pembelajaran online yaitu moodle dapat meningkatkan kemampuan interkoneksi berupa multiple level representasi bagi mahasiswa calon guru pada topik kesetimbangan asam-basa [2].

\section{METODE}

Populasi penelitian adalah seluruh siswa kelas kelas X MIA SMA N 9 Malang Tahun ajaran 2014/2015. Pengambilan sampel penelitian dilakukan dengan teknik Cluster Random Sampling dan diperoleh kelas X MIA-5 dan X MIA-6 sebagai sampel penelitian. Hal ini dikarenakan kedua kelas tersebut memiliki kemampuan awal yang sama (bersifat homogen). Instrumen penelitian terdiri dari angket self-directed learning yang menunjukkan kemampuan self-directed learning awal siswa. Tes ini diadopsi dari tes SDLRS King \& Fisher dengan koefisien reliabilitas sebesar 0,87. Sedangkan tes obyektif merupakan tes hasil belajar kognitif. Instrumen tes yang digunakan dalam penelitian ini sudah divalidasi dan diujicobakan dengan validitas isi sebesar $81,8 \%$ (sangat tinggi) dan koefisien reliabilitas sebesar 0,88 (valid dan reliabel) dihitung dengan menggunakan KR-21. Penelitian ini menggunakan desain eksperimen faktorial $2 \times 3$ yang sering disebut Two Factorial Design. Secara skematis desain eksperiment tersebut dapat digambarkan pada Tabel 1.

Tabel 1. Rancangan Two Factorial Design

\begin{tabular}{llll}
\hline Variabel Ikat & $\begin{array}{l}\text { Kemam } \\
\text { puan } \\
\text { self- } \\
\text { directed } \\
\text { learning } \\
\text { tinggi } \\
\left(\mathrm{Y}_{1}\right)\end{array}$ & $\begin{array}{l}\text { Kemam } \\
\text { puan } \\
\text { self- } \\
\text { directed } \\
\text { learning } \\
\text { sedang } \\
\left(\mathrm{Y}_{2}\right)\end{array}$ & $\begin{array}{l}\text { Kemam } \\
\text { puan } \\
\text { self- } \\
\text { directed } \\
\text { Veariabel }\end{array}$ \\
$\begin{array}{llll}\text { Bebas } \\
\text { rendah } \\
\left(\mathrm{Y}_{3}\right)\end{array}$ \\
\hline $\begin{array}{l}\mathrm{X}_{1} \mathrm{Y}_{1} \\
\mathrm{X}_{1} \mathrm{Y}_{2}\end{array}$ & $\mathrm{X}_{2} \mathrm{Y}_{3}$ \\
Moodle $\left(\mathrm{X}_{2}\right)$ & $\mathrm{X}_{2} \mathrm{Y}_{1}$ & $\mathrm{X}_{2} \mathrm{Y}_{2}$ & $\mathrm{X}_{2} \mathrm{Y}_{3}$ \\
\hline
\end{tabular}


HASIL DAN PEMBAHASAN

Pengelompokan siswa berdasarkan data kemampuan Self-Directed Learning diberikan pada Tabel 2.

Tabel 2. Pengelompokan Siswa Berdasarkan Kemampuan SDL

\begin{tabular}{lccc}
\hline Kriteria & $\begin{array}{c}\text { Klmpk } \\
\text { Moodle }\end{array}$ & $\begin{array}{c}\text { Klmpk } \\
\text { Blog }\end{array}$ & $\begin{array}{c}\text { Persentase } \\
(\%) \text { Total } \\
\text { Kelompok }\end{array}$ \\
\hline Rendah & 4 & 4 & 14,8 \\
Sedang & 8 & 10 & 33,3 \\
Tinggi & 16 & 12 & 51,9 \\
Total & $\mathbf{2 8}$ & $\mathbf{2 6}$ & $\mathbf{1 0 0}$ \\
\hline
\end{tabular}

Berdasarkan Tabel 2, diperoleh keterangan bahwa siswa yang memiliki kemampuan Self-Directed Learning (SDL) tinggi dan sedang pada kelas blog dan moodle sebanyak $85,2 \%$. Sedangkan hasil belajar kognitif siswa yang diperoleh dari data posttest yang dapat dilihat pada Tabel 3.

\begin{tabular}{lccc}
\multicolumn{4}{c}{ Tabel 3. Data Hasil Belajar Kognitif } \\
Ikatan Kimia \\
\hline Kelompok & $\begin{array}{c}\text { Jumlah } \\
\text { Siswa }\end{array}$ & Rata-Rata & SD \\
& 26 & 78,5 & 6,01 \\
Blog & 28 & 78,9 & 5,24 \\
\hline
\end{tabular}

Data hasil belajar kognitif diuji normalitas dan homogenitas terlebih dahulu sebelum melakukan uji hipotesis penelitian. Hasil uji normalitas menggunakan One-Sample Kolmogorov-Smirnov Test diperoleh bahwa skor posttest telah terdistribusi normal dengan nilai probabilitas sebesar 0,058 . Hasil uji homogenitas menunjukkan bahwa skor hasil posttest memiliki varian homogeny karena nilai probabilitasnya sebesar 0,759 dan $F_{\text {hitung }}(0,522)<F_{\text {tabel }}$ $(2,41)$. Sedangkan data hasil belajar kognitif dapat dilihat pada Tabel 4.

\begin{tabular}{ccccc} 
Tabel 4 & \multicolumn{5}{c}{ Data Hasil Belajar Kognitif } \\
Ikatan Kimia \\
\hline $\begin{array}{c}\text { Kemam } \\
\text { puan }\end{array}$ & \multicolumn{4}{c}{ Skor Hasil Belajar Kognitif } \\
KDLL & N & X & Nemok Blog & Kelompok Moodle \\
\hline Tinggi & 12 & 82,6 & 16 & X \\
Sedang & 10 & 76,7 & 8 & 80,3 \\
Rendah & 4 & 72,2 & 4 & 73,6 \\
Total & 26 & 78,5 & 28 & 78,9 \\
\hline
\end{tabular}

Dari Tabel 4 menunjukkan jika siswa dengan kemampuan self-directed learning berbeda memperoleh hasil belajar kognitif yang berbeda. Pada kelompok siswa dengan media belajar berupa blog, siswa dengan kemampuan $S D L$ memperoleh skor rata-rata hasil belajar kognitif yang lebih tinggi dibandingkan siswa dengan kemampuan $S D L$ sedang dan rendah yaitu 82,6. Sedangkan siswa dengan kemampuan SDL sedang pada kelompok moodle, memperoleh rata-rata skor hasil belajar kognitif lebih tinggi daripada siswa dengan kelompok $S D L$ tinggi dan rendah yaitu 80,7.

Tabel 5. Ikhtisar Hasil Uji ANAVA Dua Jalur

\begin{tabular}{|c|c|c|}
\hline & Hasil Uji & Kesimpulan \\
\hline $\begin{array}{l}\text { Model Web } \\
\text { based learning } \\
\text { (Pembelajaran } \\
\text { Blog dan } \\
\text { Moodle) }\end{array}$ & $\begin{array}{c}\text { Sig. }=0,528> \\
0,05 \\
F_{\text {hitung }}=0,405< \\
F_{\text {tabel }}(4,03)\end{array}$ & $\begin{array}{c}\text { Tidak ada } \\
\text { beda }\end{array}$ \\
\hline $\begin{array}{l}\text { Kemampuan } \\
\text { self-directed } \\
\text { learning siswa }\end{array}$ & $\begin{array}{c}\text { Sig. }=0,000<0,05 \\
F_{\text {hitung }}=9,241> \\
F_{\text {tabel }}(3,18)\end{array}$ & Ada beda \\
\hline $\begin{array}{l}\text { Model Web } \\
\text { based } \\
\text { learning* } \\
\text { Kemampuan } \\
\text { Self-Directed } \\
\text { Learning }\end{array}$ & $\begin{array}{c}\text { Sig. }=0,025<0,05 \\
F_{\text {hitung }}=4,009> \\
F_{\text {tabel }}(3,18)\end{array}$ & $\begin{array}{c}\text { Ada } \\
\text { interaksi }\end{array}$ \\
\hline$N=54$ & $\alpha=0,05$ & \\
\hline
\end{tabular}

Hasil uji statistic dengan ANAVA dua jalur pada Tabel 5 menunjukkan bahwa:

1. Tidak ada perbedaan hasil belajar kognitif siswa yang diajar dengan model WBL menggunakan media blog dan moodle pada materi ikatan kimia.

2. Ada perbedaan hasil belajar kognitif siswa yang diajar dengan model $W B L$ menggunakan media blog dan moodle ditinjau dari kemampuan self-directed learning siswa pada materi ikatan kimia.

3. Ada interaksi antara penggunaan model $W B L$ dan tingkat kemampuan self- 
directed learning terhadap hasil belajar kognitif siswa pada materi ikatan kimia.

Dari Tabel 5, menunjukkan ada interaksi antara penggunaan model web based learning dengan kemampuan self-directed learning siswa signifikan berpengaruh berbeda terhadap variable terikat. Artinya, siswa yang berkemampuan SDL tinggi, sedang, dan rendah yang telah dikelompokkan oleh peneliti sebelum pelaksanaan pembelajaran setelah diajar dengan model web based learning baik menggunakan media blog maupun moodle memperoleh hasil belajar yang berbeda pada taraf kepercayaan 95\%. Karena ada beda yang ditunjukkan dari hasil hipotesis $\mathrm{H}_{03}$ maka perlu dilanjutkan uji post hoc ANAVA. Berikut disajikan ringkasan data uji Post Hoc pada Tabel 6 berikut:

Tabel 6 Ringkasan Uji Post Hoc ANAVA Model WBL x Kemampuan SDL Siswa

\begin{tabular}{ccccccc}
\hline $\begin{array}{l}\text { Kelompok } \\
\text { Perlakuan }\end{array}$ & $\mathbf{X}_{\mathbf{1}} \mathbf{Y}_{\mathbf{1}}$ & $\mathbf{X}_{\mathbf{1}} \mathbf{Y}_{\mathbf{2}}$ & $\mathbf{X}_{\mathbf{1}} \mathbf{Y}_{\mathbf{3}}$ & $\mathbf{X}_{\mathbf{2}} \mathbf{Y}_{\mathbf{1}}$ & $\mathbf{X}_{\mathbf{2}} \mathbf{Y}_{\mathbf{2}}$ & $\mathbf{X}_{\mathbf{2}} \mathbf{Y}_{\mathbf{3}}$ \\
\hline $\mathbf{X}_{\mathbf{1}} \mathbf{Y}_{\mathbf{1}}$ & - & 2,004 & $9,044^{*}$ & 0,260 & $16,836^{*}$ & $6,450^{*}$ \\
$\mathbf{X}_{\mathbf{1}} \mathbf{Y}_{\mathbf{2}}$ & & - & $10,59^{*}$ & 0,667 & $4,851^{*}$ & 2,396 \\
$\mathbf{X}_{\mathbf{1}} \mathbf{Y}_{\mathbf{3}}$ & & & - & $11,818^{*}$ & 1,001 & 3,041 \\
$\mathbf{X}_{\mathbf{2}} \mathbf{Y}_{\mathbf{1}}$ & & & & - & $8,231^{*}$ & 3,728 \\
$\mathbf{X}_{\mathbf{2}} \mathbf{Y}_{\mathbf{2}}$ & & & & & - & 0,456 \\
$\mathbf{X}_{\mathbf{2}} \mathbf{Y}_{\mathbf{3}}$ & & & & & & - \\
\hline *) ada perbedaan yang signifikan & & & & &
\end{tabular}

Berdasarkan Tabel 6, dapat disimpulkan jika pada kelas blog antara siswa dengan $S D L$ tinggi memperoleh hasil belajar kognitif yang berbeda dengan hasil belajar kognitif siswa dengan $S D L$ sedang dan rendah. Sedangkan antara siswa dengan SDL sedang memperoleh hasil belajar yang relative sama dengan siswa yang memiliki $S D L$ rendah. Sedangkan pada kelas moodle, hasil belajar kognitif antara siswa dengan $S D L$ tinggi tidak berbeda dengan hasil belajar kognitif siswa dengan $S D L$ sedang dan rendah. Sedangkan antara siswa dengan SDL sedang memperoleh hasil belajar yang berbeda dengan siswa yang memiliki $S D L$ rendah.

\section{SIMPULAN}

Berdasarkan tujuan penelitian, hasil penelitian dan pembahasan yang disajikan, maka diperoleh kesimpulan bahwa:

1. Tidak terdapat perbedaan hasil belajar kognitif siswa baik yang dibelajarkan dengan media moodle maupun media blog. Kedua penggunaan media tersebut efektif digunakan dalam pembelajaran dengan model web based learning.

2. Siswa dengan tingkat kemampuan selfdirected learning yang berbeda memiliki hasil belajar kognitif yang berbeda baik yang dibelajarkan dengan media moodle maupun media blog.

3. Di antara faktor model web based learning dengan kemampuan selfdirected learning siswa terdapat interaksi dengan hasil belajar kognitif siswa.

\section{DAFTAR PUSTAKA}

[1] K. C. Timberlake \& W. Timberlake. Basic Chemistry (4 ${ }^{\text {th }}$ Edition). USA: Pearson Education Inc, 2014.

[2] I. F. Liliasari, \& W. Sopandi. "Pembelajaran Berbasis Web untuk Meningkatkan Kemampuan Interkoneksi Multiple level Representasi Mahasiswa Calon Guru pada Topik Kesetimbangan Larutan Asam-Basa”. Jurnal Chemica, vol. 12, no. 1, pp. 14-24, 2011.

[3] G. Sirhan. "Learning Difficulties in Chemistry: An Overview". Journal of 
Turkish Science Education, vol. 4, no. 2, pp. 2-20, 2007.

[4] H. D. Barke, A. Hazari, dan S. Yitbarek. Misconceptions In Chemistry: Addressing Perceptions In Chemical Education. Berlin: SpringerVerlag, 2009.

[5] E. Mayasari, E. Enawaty, dan Erlina. "Pengaruh Penggunaan Buku Ajar Ikatan Ionik dengan Pendekatan Multi Representasi terhadap Prestasi Belajar Siswa", 2012, [Online], Tersedia: http://jurnal.untan.ac.id.pdf. [Diakses 15 Februari 2014]

[6] T. Furakawa, N. Shirakawa, N. "ICT Use and Increasing Openness in Higher Education (Advanced elearning and Open Educational Resources)". Science and Technology Foresight Center: Japan, 2011.

[7] A. Chavan. "Developing an Open Source Content Management Strategy for E-Government. $42^{\text {nd }}$ Annual Conference of the Urban", 2004, [Online], Tersedia: http://downloads2.esri.com/campus/up loads/library/pdfs/35869.pdf. [Diakses 3 April 2014]

[8] J. L. Wendt \& A. Rockinson-Szapkiw. "Synchronous and Asynchronous Communication Technologies in Online Group Work: Implication for Design and Practice". Society for Information Technology \& Teacher Education International Conference: Association for the Advancement of Computing in Education (AACE), 2015.
[9] Z. Own. "The Application of an Adaptive, Web-Based Learning Environment on Oxidation-Reduction Reactions". International Journal of Science and Mathematics Education, vol. 8, no. 1, pp. 1-23, 2010.

[10] H. Özmen, "The Influence of Computer-Assisted Instruction on Students' Conceptual Understanding of Chemical Bonding and Attitude Toward Chemistry: A Case for Turkey". Computers \& Education, vol. 51, no. 1, pp. 423-438, 2008.

[11] R. M. Kelly \& L. L. Jones. "Exploring How Different Features of Animations of Sodium Chloride Dissolution Affect Students' Explanations". Journal of Science Education and Technology, vol. 16, pp. 413-429, 2007.

[12] E. Şenyuva \& H. Kaya, "Effect Self Directed Learning Readiness of Nursing Students of the Web Based Learning". Procedia Social and Behavioral Sciences, pp. 386-392, 2014.

[13] P. N. Chou. "Effect of Students' SelfDirected Learning Abilities on Online Learning Outcomes: Two Exploratory Experiments in Electronic Engineering". International Journal of Humanities and Social Science, vol. 2, pp. 172-179, 2012.

[14] Zyainuri \& E. Marpanaji. "Penerapan E-Learning Moodle untuk Pembelajaran Siswa yang Melaksanakan Prakerin". Jurnal Pendidikan Vokasi, vol. 2, no. 3, pp. 410-426, 2012. 